\title{
Production Biodiesel from Coconut Oil Using Microwave: Effect of Some Parameters on Transesterification Reaction by $\mathrm{NaOH}$ Catalyst
}

\author{
A. Suryanto, S. Suprapto, M. Mahfud* \\ Department of Chemical Engineering Faculty of Industrial Technology, Sepuluh Nopember \\ Institute of Technology, Sukolilo Surabaya 60111, Indonesia
}

Received: 15th January 2015; Revised: 10th March 2015; Accepted: 15th March 2015

\begin{abstract}
The purpose of this research was to study the effect of reaction time and $\mathrm{NaOH}$ catalyst in transesterification of coconut oil enhanced by microwave and to obtain a biodiesel. Reaction was conducted in batch reactor which equipped by microwave. Coconut oil contains saturated fatty acids about $70 \%$ with medium chain $\left(\mathrm{C}_{8}-\mathrm{C}_{14}\right)$, especially lauric acid and myristic acid. The reaction was initiated by mixing oil and methanol with oil to methanol mole ratios of 1:3, 1:6, 1:9 and 1:12, catalyst concentration of 0.1 , $0.15,0.2,0.25$ and 0.3 wt.\%, as well as setting electrical power at 100, 264 and $400 \mathrm{~W}$. The reaction times were of $0.5,1,1.5,2,2.5,3$ and $3.5 \mathrm{~min}$. The result showed that microwave could be employed as an energy source and was able to accelerate the transesterification process to produce biodiesel using $\mathrm{NaOH}$ catalyst. The biodiesel yields increase with increasing microwave power. The highest yield of biodiesel obtained was of $97.37 \%$ with reaction conditions set at 0.2 wt.\% catalyst, a reaction time of 2 min, molar ratio of methanol to oil 1:9 and microwave power of 400 watt. (C) 2015 BCREC UNDIP. All rights reserved.
\end{abstract}

Keywords: transesterification; biodiesel; coconut oil; microwave; $\mathrm{NaOH}$ catalyst

How to Cite: Suryanto, A., Suprapto, S., Mahfud, M. (2015). Production Biodiesel from Coconut Oil Using Microwave: Effect of Reaction Time on Transesterification Reaction by NaOH Catalyst. Bulletin of Chemical Reaction Engineering \& Catalysis, 10 (2): 162-168. (doi:10.9767/bcrec.10.2.8080.162-168)

Permalink/DOI: http://dx.doi.org/10.9767/bcrec.10.2.8080.162-168

\section{Introduction}

The use of petroleum still dominates the energy consumption in Indonesia, especially in the transport sector. Utilization of energy in Indonesia had significantly increased about $7.7 \%$ in the past 19 years and expected to incline in the coming years as previously reviewed study

* Corresponding author.

E-mail: mahfud@chem-eng.its.ac.id (Mahfud)

Telp: +62-815-522-3477, Fax : +62-31-5946480
[1]. Indonesia has turned from a net exporter to a net importer of oil in recent years. At it faces heavy challenges since the international price of petroleum increases continually. An alternative energy is indispensable as the use of petroleum increases year by year [1]. One of the renewable sources, which can be developed to be bio-fuel, is a vegetable oil. In Indonesia, biofuels were still being developed from some renewable materials to substitute a part of fossil fuel and it, as tropical country, is a source of vegetable oils as follows: food oils, such as palm and coconut oil, non-edible oils-Jatropha curcas, neem and others [2,3,4]. 
The use of microwave is an alternative to manufacture of biodiesel to enhance the conversion process. With the development of the manufacturing process, including the development of alternative fuel sources of energy, and one of them is that microwaves can accelerate the reaction $[5,6,7,8,9]$. Wave radiation is absorbed by polar molecules-water, sugars and fats as well as other substances that atoms are excited and produced heat. Heating takes place simultaneously and uniformly on the excited atoms and produce heat at the same time. The microwaves are basically electromagnetic radiations, having electric field component and a magnetic field component. The former component is responsible for the dielectric heating. Many molecules (such as those of water, alcohol, fats, etc.) are electric dipole and therefore they rotate as they try to align themselves with the alternating electric field of the microwaves [10]. The use of microwaves provides many advantages as follows: fast startup time, faster heating, efficient energy and the lower process cost, easy to monitor, precise, selective heating and the better quality of the final product $[7,8]$. Microwave irradiation has been an alternative heating system in transesterification over the past few years [11]. As a result and short separation time have been obtained [8]. Biodiesel can be produced at a lower temperature and shorter reaction time with an alkali catalyst compared to those required for an acid catalyst $[9,10,11]$.

Coconut oil as other vegetable oils are compounds consisting of various kinds of triglyceride fatty acids and about $90 \%$ are saturated fatty acid compounds. Coconut oil is rich in fatty acids are chain $\left(\mathrm{C}_{8}-\mathrm{C}_{12}\right)$, especially lauric acid and myristic acid. The composition of fatty acids in coconut oil is caprylic acid $6.601 \%$, capric acid $5.71 \%$, lauric acid $46.46 \%$, myristic acid $20.57 \%$, palmitic acid $9.16 \%$, acid stearic $2.94 \%$, oleic acid $7.21 \%$ and linoleic acid $1.65 \%$ [3]. Coconut oil as a raw material has advantages than other vegetable oils, it contains medium chain fatty acids about $70 \%$ making it possible to obtain other fuels such as kerosene or jet fuel.

This research aims to study the development of the process of making biodiesel from coconut oil using a microwave, among others; the effect of reaction time, molar ratio of oil to methanol, catalyst concentration and microwave power to obtain yield. In addition, the use of microwaves as a source of energy, which also can increase the activity of the catalyst so that the reaction is faster and can increase the yield.

\section{Materials and Methods}

\subsection{Material}

The present study used refinery commercial coconut oil (Barco Co) whose water and free fatty acid (FFA) content were about 0.09 wt.\% and 0.05 wt.\%, respectively. The alcohol and catalyst used in the present study were methanol and $\mathrm{NaOH}$, respectively. Methanol commercial (purity: 96 \%) was purchased from Brataco Co. Ltd. (Indonesia). The $\mathrm{NaOH}$, p.a MERCK, purity: $99 \%$ were obtained from a local chemical supplier (O.V. Chemicals, Co Ltd).

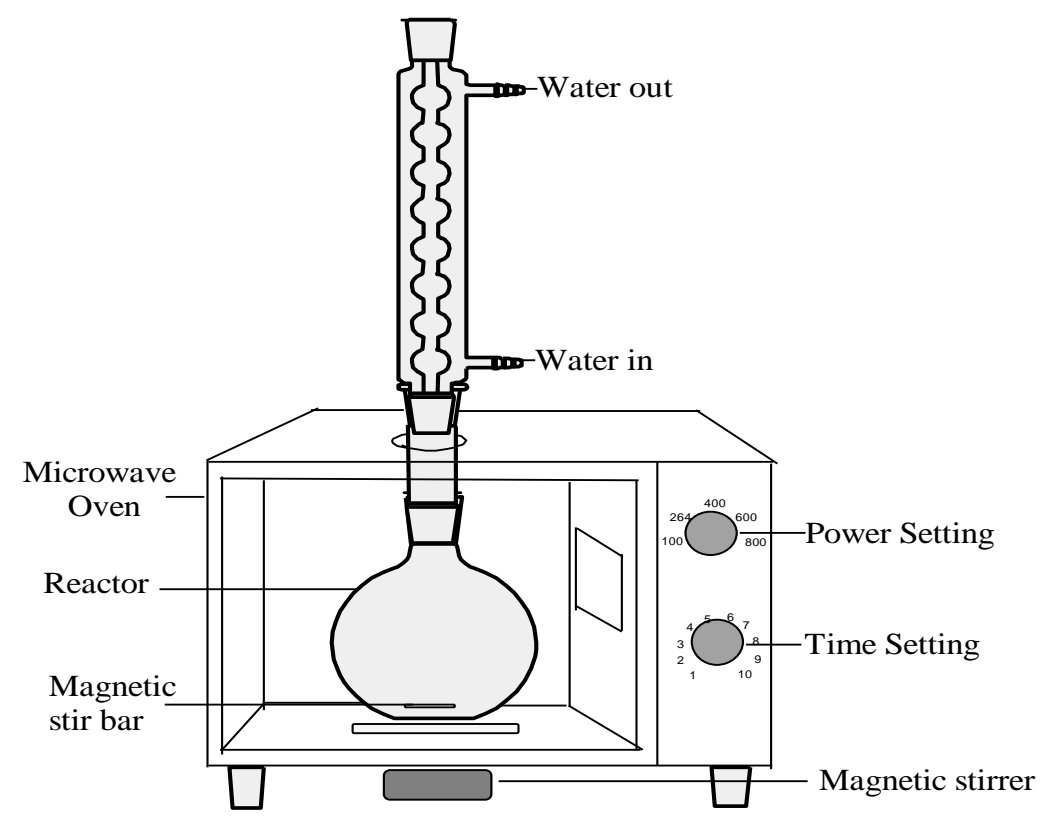

Figure 1. The experimental setup for transesterification process assisted by microwave. 


\subsection{Apparatus}

The production of biodiesel was conducted in a batch reactor using microwave radiation as heating sources. The reaction study was performed by varying the microwave power and reaction time. The design of equipment used in this study is shown in Figure 1. The reactor is a flat bottom flask made from Pyrex glass equipped by magnetic stirrer. The microwave oven commercial used in this study is Electrolux Microwave EMM2007X with a frequency of $2.45 \mathrm{GHz}$, power output from 100 to 800 watts and 0 to 30 min time setting.

\subsection{Experimental Procedures}

Transesterification reactions were carried out under microwave heating in order to see the effect using microwave on the reaction time and concentration catalyst of the transesterification process. Transesterification were done in the presence of $\mathrm{NaOH}$ catalyst $(0.1,0.15,0.2$, 0.25 and 0.3 wt.\%), oil to methanol molar ratio of 1:3, 1:6, 1:9, and 1:12. First of all coconut oil was introduced in the reactor and then mixture of methanol and $\mathrm{NaOH}$ were added. The reaction was started by turned on the microwave power of 100 watts and set reaction time 0.5 $\mathrm{min}$. The process was repeated for other variables reaction of 264 and 400 watts of power and reaction times of $1,1.5,2,2.5,3$ and 3.5 minutes.

After completion of the reaction, the product was kept in separating funnel over night for separating methyl ester and glycerol. The methyl ester was first washed with in warm water for three times. Finally the product was dried at $110^{\circ} \mathrm{C}$ for $1 \mathrm{~h}$.

Table 1. Composition of fatty acid coconut oil

\begin{tabular}{lcc}
\hline \multicolumn{1}{c}{ Fatty Acid } & Chemical formula & $\%$.wt \\
\hline Caprylic acid & $\mathrm{C}_{8} \mathrm{H}_{24} \mathrm{O}_{2}$ & 0.27 \\
Capric acid & $\mathrm{C}_{10} \mathrm{H}_{26} \mathrm{O}_{2}$ & 3.91 \\
Lauric acid & $\mathrm{C}_{12} \mathrm{H}_{28} \mathrm{O}_{2}$ & 41.21 \\
Miristic acid & $\mathrm{C}_{14} \mathrm{H}_{30} \mathrm{O}_{2}$ & 23.90 \\
Palmitic acid & $\mathrm{C}_{16} \mathrm{H}_{32} \mathrm{O}_{2}$ & 16.50 \\
Stearic acid & $\mathrm{C}_{18} \mathrm{H}_{36} \mathrm{O}_{2}$ & 3.14 \\
Oleic acid & $\mathrm{C}_{18} \mathrm{H}_{34} \mathrm{O}_{2}$ & 9.14 \\
Linoleic acid & $\mathrm{C}_{18} \mathrm{H}_{30} \mathrm{O}_{2}$ & 1.61 \\
\hline
\end{tabular}

\subsection{Analysis of Product}

The biodiesel product was analyzed for viscosity (ASTM D445), specific gravity (ASTM D1298), flash point (ASTM D93) and acid number (ASTM D 664) to assess their quality. All experiment were carried out triplicate and mean values were reported.

The concentrations of biodiesel were analyzed by gas chromatography (Agilent 6890 GC) equipped with a capillary column Agilent $19095 \mathrm{~N}-123$ INNOWAX, (30 m x $0.53 \mathrm{~mm} \times$ $1 \mu \mathrm{l})$ and a flame ionization detector (FID). Helium was used as the carrier gas. The yield of biodiesel was calculated from the content of methyl ester analyzed by GC with the following equation:

$$
\text { Yield }(\%)=\frac{\left(W_{\text {biodiesel }} . C_{\text {biodiesel }}\right)}{W_{\text {coconutoil }}} \times 100 \%
$$

where, $W_{\text {biodiesel }}$ is actual weight of biodiesel produced from experiment (g). $W_{\text {coconut oil }}$ is weight of coconut oil used in this study (g). Meanwhile, $C_{\text {biodiesel }}$ is content of methyl ester inside biodiesel measured by GC.

\section{Results and Discussion}

The fatty acid composition of the coconut oil was obtained by Gas Cromatography (Table 1). The content of fatty acids in coconut oil are used in this study as show in Table 1, the fatty acid to $\left(\mathrm{C}_{8}-\mathrm{C}_{14}\right)$ containing approximately $70 \%$, while for the chain $\left(\mathrm{C}_{16}-\mathrm{C}_{18}\right)$ of about $30 \%$, this indicates that coconut oil is rich in saturated fatty acids, saturated fatty acids which are stable at high temperatures so it is best used as a raw material for the manufacture of alternative fuels, especially biodiesel, in addition to having the potential to obtain other fuels such as biokerosene, etc. In this study, the biodiesel is prepared by single transesterification process assisted by microwave using $\mathrm{NaOH}$ catalyst. The results obtained are biodiesel golden brown on top and brown glycerol is at the bottom. Biodiesel produced was analyzed using Gas Cromatography as shown in Figure 2.

\subsection{The effects of molar ratio with oil to methanol}

The amount of methanol required for transesterification was analyzed in terms of the molar ratio with respect to triglyceride. The molar ratio triglyceride to methanol stoichiometrically was $1: 3$. However, this is not sufficient to complete the reaction. Higher molar ratio is re- 
quired to complete the reaction at a satisfactory rate [12]. The experiment was conducted by altering the ratio molar of oil to methanol (1:3, 1:6, 1:9 and 1:12). This investigation aimed to analyze the influence of ratio respect to yield of biodiesel. The effect of molar ratio on the yield of ester content is shown in Figure 3. From this figure show that an increase from 1:3 to $1: 9$ caused a significant in yield $27.79 \%$ to $96.65 \%$, when the molar ratio was further increased to $1: 12$, the yield decrease from 96.65 to $94.51 \%$. Therefore, a molar ratio of 1:9 is most suitable for synthesis biodiesel from coconut oil. In practice a higher molar ratio is needed for the reaction, because the transesterification reaction is reversible. Furthermore, biodiesel and glycerol are miscible due to the use of excess methanol $[13,14]$. However methanol is strong medium for absorbing microwaves, and thus the excess methanol may absorb microwave energy and reduce the microwave power [9]. Consequently, the molar ratio of methanol to oil should not be excessive, and 9 was considered the most suitable level in this experimental system.

\subsection{The effects of microwave power}

The experiment to investigate the effect of power microwave carried out with the following condition 0.3 wt.\% $\mathrm{NaOH}$ catalyst, a reaction times 3.5 min a methanol ratio to oil molar ratio 1:9. The results is shown in Figure 4. The yields biodiesel increased with increasing power. The yields were $64.56 \%, 85.98 \%$, and $96.65 \%$ for microwave power 100, 264 and 400 W respectively. Similar results were previously reported by other authors $[15,16]$. In addition the microwave power output must not be too high, as it may cause damage to organic molecules such as triglycerides [17]. The energy required for the microwave method is 23 times lower than that required for the conventional method similarly [16]. Microwave emission increases reaction rates and product yields and shorten the reaction time when compared to the thermal reaction. Increasing the speed of reaction that is triggered by the microwave radiation, causing friction resulting in heat [11]. Rapid temperature rise is to encourage an increased rate of reaction, because the reaction rate is a function of temperature. These results suggest that appropriate power dissipation control will effect in effective use of microwave energy and reduce energy consumption.

\subsection{The effects of reaction time}

Transesterification reaction time is very important to do an evaluation for determining and ensuring the reaction process can be run properly. Experiment was carried out with various reaction times $(0.5,1,1.5,2,2.5,3$ and $3.5 \mathrm{~min}$ ) to investigate the effects of reaction time on the yield. The process was conducted at molar ratio $1: 9$ and microwave power $400 \mathrm{~W}$. As shown in Figure 5, the yield of biodiesel

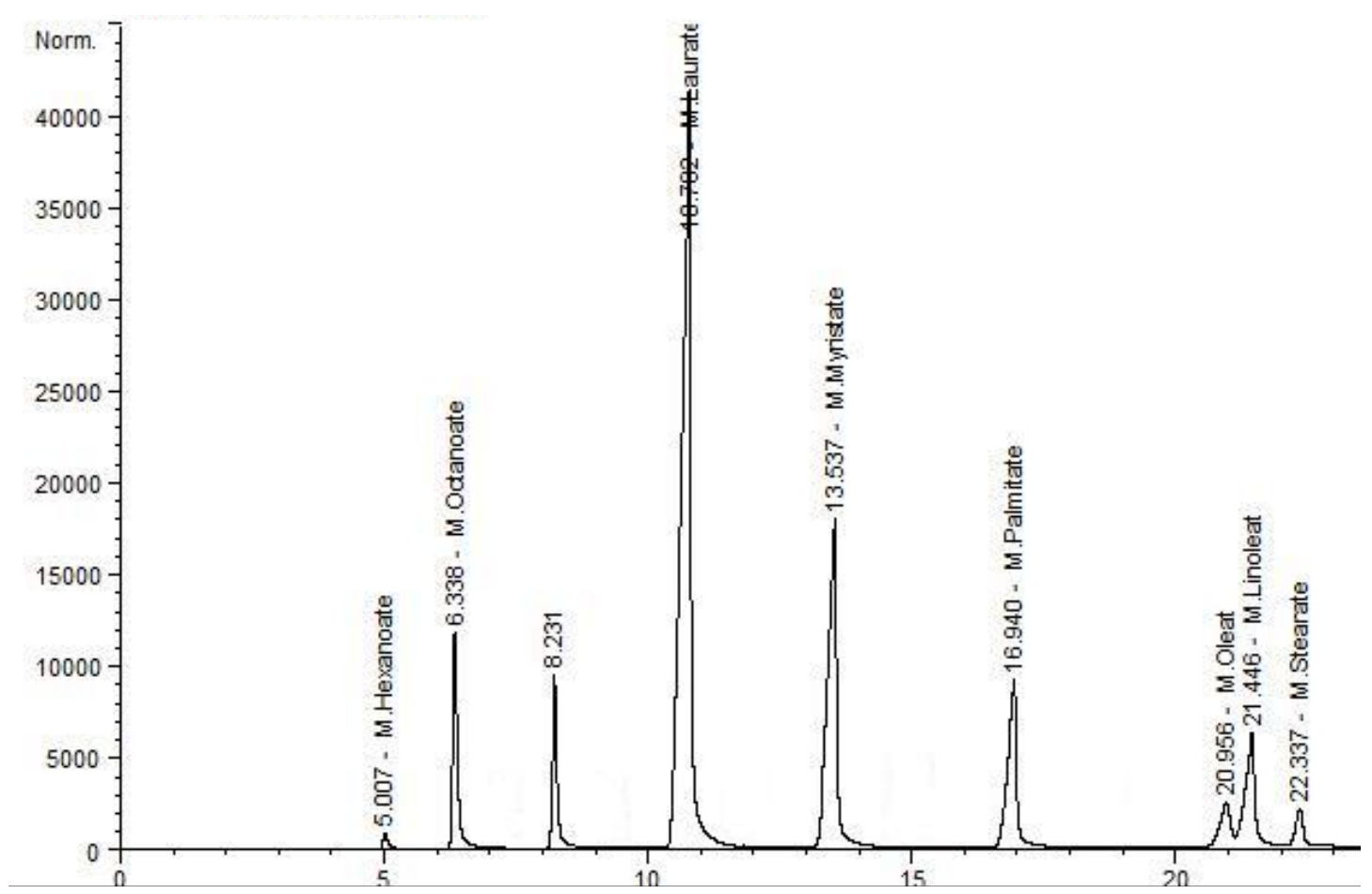

Figure 2. GC Chromatogram of produced methyl ester using $\mathrm{NaOH}$ as a catalyst 
were $54.59 \%, 71.11 \%, 81.33 \%, 97.37 \%, 97.22 \%$, $97.06 \%$ and $96.93 \%$ for reaction time of $0.5,1$, $1.5,2,2.5,3$ and $3.5 \mathrm{~min}$, respectively. An increase in reaction time from 0.5 to $2 \mathrm{~min}$ caused a significant enhancement of biodiesel yield, which the decrease with further increase to $3.5 \mathrm{~min}$. These results may be attributed to the incomplete transesterification reaction between methanol and oil in the shorter reaction; the longer reaction had higher reaction temperature, resulting in greater solubility of glycerin. In this study the reaction process occurs during the existence of the microwave emission. Therefore, the reaction time equal to the emission of microwaves. Microwave emission of molecules and ions can activate the polar as methanol. Continuous electromagnetic field interacts with the dipole molecules and ions that cause excitation and generates heat quickly [9].

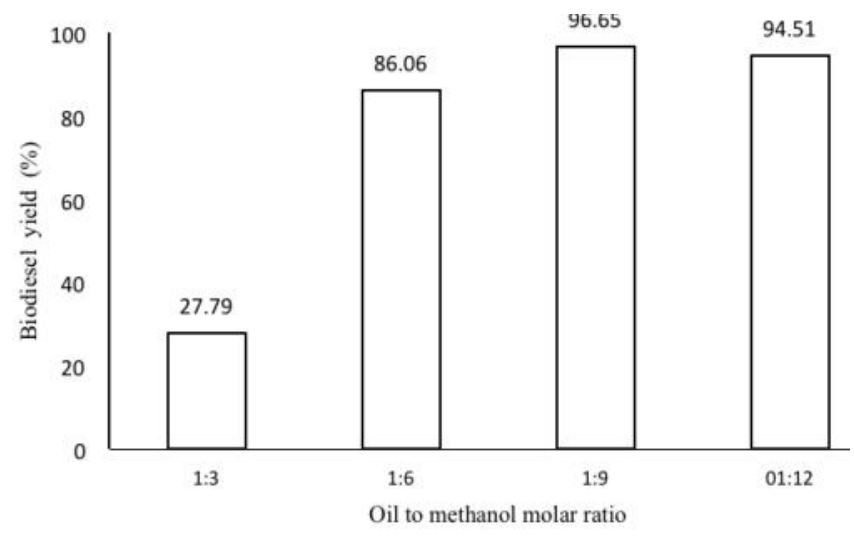

Figure 3. Effect of molar ratio of oil to methanol $(1: 3,1: 6,1: 9$ and $1: 12)$ with microwave power $400 \mathrm{~W}, 0.3$ wt.\% $\mathrm{NaOH}$ and reaction time $3.5 \mathrm{~min}$.

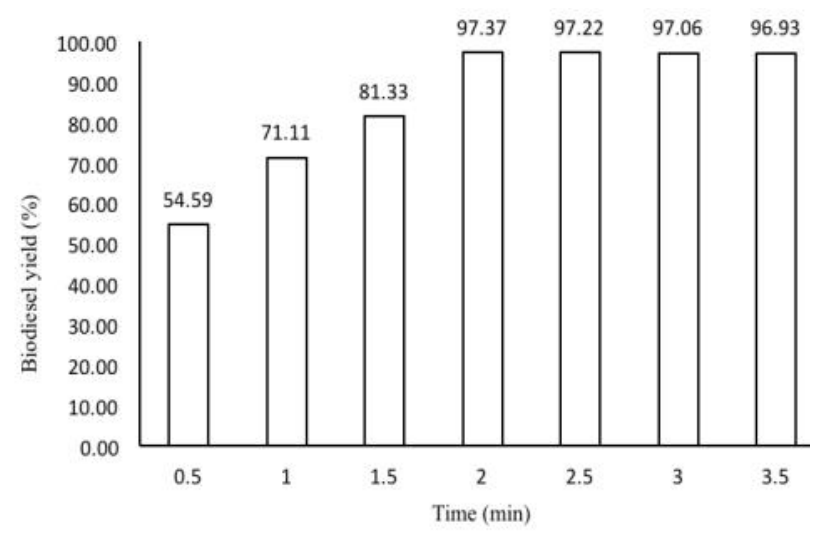

Figure 5. The effect of reaction times on biodiesel yields with 1:9 molar ratio of oil to methanol, 0.2 wt.\% $\mathrm{NaOH}$ and microwave power $400 \mathrm{~W}$
Increased reaction time will be followed increase in reaction temperature. The reaction temperature has a great influence on the course of the reaction. Meanwhile, the reaction temperature is approaching the point of methanol learners will cause soap formation reactions that affect biodiesel yield reduction. Biodiesel yield obtained in this present work is higher than published data [11]. Azcan and Danisman found that the yields of rapeseed oil were $92.0 \%$ for reaction times $5 \mathrm{~min}$, respectively, with 1 wt.\% $\mathrm{NaOH}$, a methanol to oil molar ratio of $1: 6$, and a microwave power of $1200 \mathrm{~W}$ [11].

\subsection{The effect of catalyst concentration}

In general, the use of a catalyst with a high concentration resulted in faster reaction rates. However, an excessive amount of catalyst will

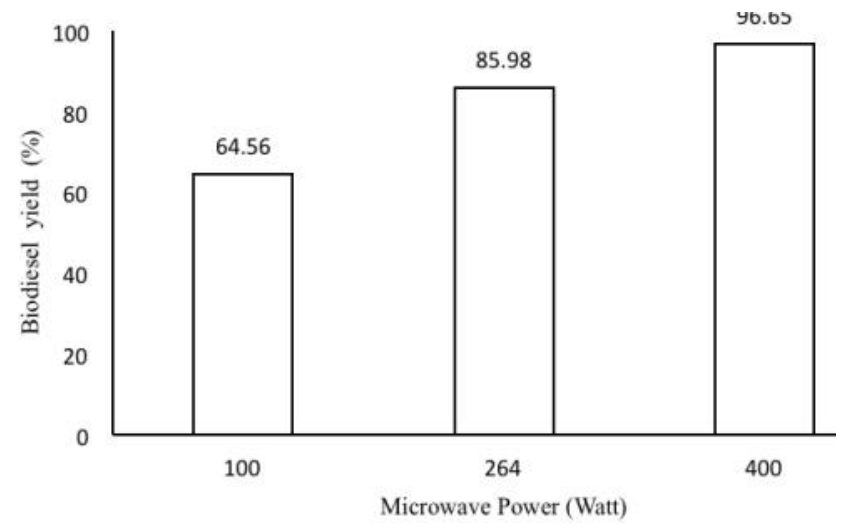

Figure 4. Effect of microwave power (100, 264 and $400 \mathrm{~W}$ ) with molar ratio $1: 9$, reaction time of $3.5 \mathrm{~min}$ and $0.3 \mathrm{wt} . \% \mathrm{NaOH}$.

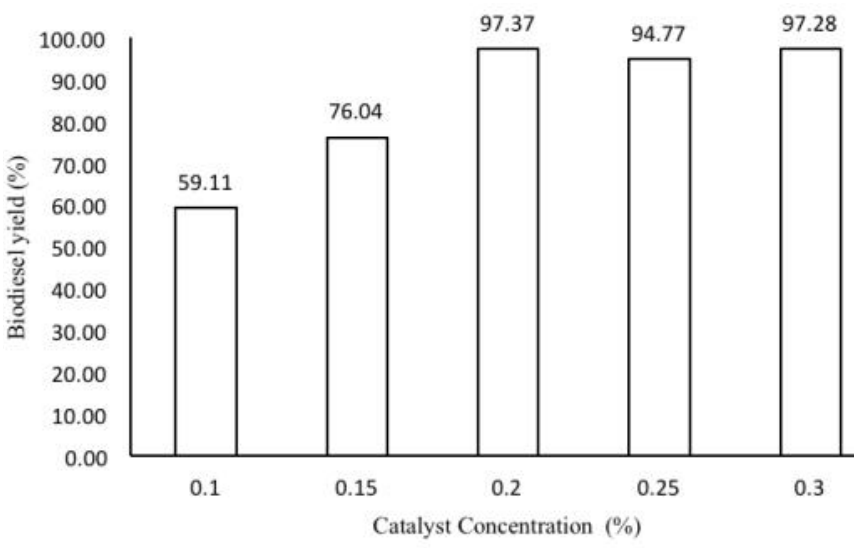

Figure 6. The effect of $\mathrm{NaOH}$ concentration on biodiesel yields with reaction time of $2 \mathrm{~min}, 1: 9$ molar ratio of oil to methanol, and microwave power $400 \mathrm{~W}$ 
lead to the formation of soap, which increase the viscosity of the reactants and there is difficulty in separating the product formed. Therefore, the amount of catalyst used is a very important parameter to obtain large quantities considered conversion results. In this study, $\mathrm{NaOH}$ catalyst concentrations and reaction time were $0.1-0.3$ wt.\%, 2 min, while methanol to oil molar ratio was 1:9 and microwave power $400 \mathrm{~W}$ as shown in Figure 6.

In this Figure 6 shows that the yields of biodiesel are relatively low when the catalyst concentration of 0.1 wt.\%. However, if the catalyst concentration is more than $0.2-0.3 \mathrm{wt} \%$ catalyst used there is a tendency of biodiesel obtained almost the same. Moreover, Dorado et al. concluded that the addition of a large amount of alkali catalyst would give rise to the formation of emulsions, increasing the viscosity even lead to gel formation [18]. These conditions also inhibit the separation of glycerol and the result is no dilution of the methyl ester, thereby reducing the product of biodiesel [19].

\subsection{Properties of Produced Biodiesel}

The quality of biodiesel is important for usage in a diesel engine. To find biodiesel that has been generated, it is necessary to do some test parameters of biodiesel in accordance with the Indonesian National Standard (SNI). Test biodiesel include moisture content, density, viscosity, acid number, sulfur content, and flash point in Table 2. The density of biodiesel obtained was $0.85 \mathrm{~g} / \mathrm{ml}$, which met SNI-2012 standard. The kinematic viscosity was 2.80 $\mathrm{mm}^{2} / \mathrm{s}$ at $40{ }^{\circ} \mathrm{C}$, while the standard was at 2.30 $6.00 \mathrm{~mm}^{2} / \mathrm{s}$. The measurement of product flash point gave $125{ }^{\circ} \mathrm{C}$, which fulfilled in the range required by Indonesia National Standard (>100 $\left.{ }^{\circ} \mathrm{C}\right)$. The data show that the biodiesel quality requirements satisfied the Indonesian National Standard. The obtained biodiesel can be considered as a fuel as substitute or additive for diesel.

\section{Conclusion}

The time of the biodiesel preparation could be shortened by using microwave compared to those conventional methods. Effects of reaction time and microwave power on the product showed that the increase of power could reduce reaction time. The highest yield of biodiesel obtained was of $97.37 \%$ at microwave power 400 $\mathrm{W}, 0.2 \mathrm{wt} . \% \mathrm{NaOH}$ for period of $2 \mathrm{~min}$ and molar ratio of oil to methanol of 1:9. The quality of obtained biodiesel in this study meets the standards and regulations established biodiesel (SNI-2012).

\section{Acknowledgements}

The authors would like to thank the Higher Education Department of Indonesia for financial support (2013-2014) and crews of process laboratory Sepuluh Nopember Institute of Technology.

\section{References}

[1] Hasan, M.H., Mahlia, T.M.I., Nur, H. (2012). A Review Our Energy Scenario and Sustainable Energy in Indonesia, Renewable and Sustainable Energy Reviews, 16: 2316-2328.

[2] Directorate of Agricultural Processing. (25 November 2014). Development of Coconut Oil, Citing Internet Sources. URL http://www.agribisnis.deptan.co.id.

[3] Dauqan, E.M.A., Sani, H.A., Abdullah, A., Kasim, Z.M. (2011). Fatty Acids Composition of Four Different Vegetable Oil (Red Palm Olein, Palm Oil, Corn Oil, and Coconut Oil) by Gas Chromatography. In Proceeding International Conference on Chemistry and Chemical Engineering, 31-34. Singapore : IACSIT Press.

[4] Motasemi, F., Ani, F.N. (2012). A Review on Microwave Assisted Production of Biodiesel. Renewable and Sustainable Energy Reviews, 16: 4719-4733.

Tabel 2. Comparisons of biodiesel product with Indonesia National Standard (SNI)

\begin{tabular}{cccc}
\hline Physical properties & Unit & $\begin{array}{c}\text { Indonesian National } \\
\text { Standar (SNI-2012) }\end{array}$ & $\begin{array}{c}\text { Biodiesel } \\
\text { (methyl ester) }\end{array}$ \\
\hline Density & $\mathrm{g} / \mathrm{ml}, 25^{\circ} \mathrm{C}$ & $0.85-0.89$ & 0.85 \\
Kinematic viscosity & $\mathrm{mm} / \mathrm{s}, 40^{\circ} \mathrm{C}$ & $2.3-6.0$ & 2.80 \\
Acid number & $\mathrm{mg} \mathrm{KOH} / \mathrm{g}$ & $<0.6$ & 0.07 \\
Sulfur content & $\%$ & $<100$ & 0.01 \\
Flash Point & ${ }^{\circ} \mathrm{C}$ & $>100$ & 125 \\
\hline
\end{tabular}


[5] Oliveira, A.N., Costa, L.R.S., Pires, L.H.O., Nascimento, L.A.S., Angelica, R.S., Costa, C.E.F., Zamian, J.R., Filho, G.N.R. (2013). Microwave Assisted Preparation of a New Esterification Catalyst from Wasted Flint Kaolin. Fuel, 103: 626-631.

[6] Manco, I., Giordani, L., Vaccari, V., Oddone, M. (2011). Microwave Technology for The Biodiesel Production: Analytical Assesments. Fuel, 95: 108-112.

[7] Kumar, R., Kumar, G.R., Chandrashekar, N. (2011). Microwave Assisted Alkali Catalyzed Transesterification of Pongamia Pinnata Seed Oil for Biodiesel Production. Bioresources Technology, 102: 6617-6620.

[8] Hsiao, M.C., Lin, C.C., Chang, Y.H. (2011). Microwave Irradiation Assisted Transesterification of Soybean Oil to Biodiesel Catalyzed by Nanopowder Calcium Oxide. Fuel, 90: 1963-1967.

[9] Gude, V.G., Patil, P., Guerra, E.M, Nirmalakhandan, S.D.N. (2013). Microwave Energy Potensial for Biodiesel. Sustainable Chemical Processes, 1(5): 1-31.

[10] Jiputti, J., Kitiyanan, B., Rangsunnivit, P., Bunyakiat, K., Attanatho, L., Jenvanitpanjakul, P. (2006). Transesterification of Kernel Oil and Crude Coconut Oil by Different Solid Catalysts. Chemical Engineering Journal, 116: $61-66$

[11] Azcan, N., Danisman, A. (2008). Microwave Assisted Transesterification of Rapeseed Oil, Fuel, 87: 1781-1788.
[12] Demirbas, A. (2002). Biodiesel from Vegetable Oils via Transesterification in Supercritical Methanol. Energy Conversion and Management, 43: 2349-2356.

[13] Yuan, H., Yang., B.I., Zhu, G.I. (2009). Synthesis of Biodiesel Using Microwave Absorption Catalysts. Energy \& Fuels, 23: 548-552.

[14] Ma, F., Hanna, M.A. (1999). Biodiesel Production : A Review, Bioresources Technology, 70: $1-17$.

[15] Groisman, Y., Gedanken, A. (2008). Continuous Flow, Circulating Microwave System and Its Application in Nanoparticle Fabrication and Biodiesel Synthesis. Journal of Physical Chemistry, 112: 8802-8808.

[16] Pathil, P.D, Gude, V.G, Camacho, L.M., Deng, S. (2010). Microwave Assisted Catalytic Transesterification of Camela Sativa Oil. Energy \& Fuels, 24: 1298-1304.

[17] Saifuddin, N., Chua, K.H. (2004). Production of Ethyl Ester from Used Frying Oil : Optimization of Transesterification Process Using Microwave Irradiation. Malaysian Journal of Chemistry, 6: 77-82.

[18] Dorado, M.P., Ballesteros, F., Lopes, F.J., Mittelbach, M. (2004). Optimization of Alkali Catalyzed Transeterification of Brassica Carinata Oil for Biodiesel Production. Energy Fuel, 18: 77-83

[19] Galema, A.S. (1997). Microwave Chemistry. Chemical Society Reviews, 26: 233-238. 